\title{
Microsurgical Resection of Tuberculum Sellae Meningioma through Left Cranio-orbital Approach
}

\author{
Mirza Pojskić1 Kenan I. Arnautović ${ }^{2}$ \\ ${ }^{1}$ Department of Neurosurgery, University of Marburg, \\ Marburg, Germany \\ 2 Semmes Murphey Neurologic and Spine Institute, Department of \\ Neurosurgery, University of Tennessee Health Science Center, \\ Memphis, Tennessee, United States
}

\author{
Address for correspondence Kenan I. Arnautović, MD, PhD, Semmes \\ Murphey Neurologic and Spine Institute, Department of \\ Neurosurgery, University of Tennessee Health Science Center, 6325 \\ Humphreys Boulevard, Memphis, TN 38120, United States \\ (e-mail: kenanarnaut@yahoo.com).
}

J Neurol Surg B 2018;79(suppl S2):S223-S224.

\begin{abstract}
Keywords

- tuberculum sellae meningioma

- suprasellar meningioma

- cranio-orbital skull base approach

In this video clip, the authors present the resection of a tuberculum sellae meningioma with compression of the left optic nerve and a chiasm ( - Fig. 1) through a standard cranial orbital (CO) skull base approach. ${ }^{1-3}$ The key step in the tumor resection was microsurgical dissection of left and right A1 segments of the anterior cerebral artery and the anterior communicating artery and the separation of the tumor from these vascular structures. This was followed by careful separation of the meningioma from both optic nerves, the chiasm and the pituitary stalk. The final step was coagulation and resection of the tumor origin on the dura of the tuberculum sellae, devascularizing the tumor. Once this was achieved, the tumor was removed. Using this approach, an optimal surgical corridor to the sellar area was provided while minimizing the retraction of frontal and temporal lobes.

The link to the video can be found at: https://youtu.be/O59Fj2dNXB0.
\end{abstract}

Conflict of Interest

None.

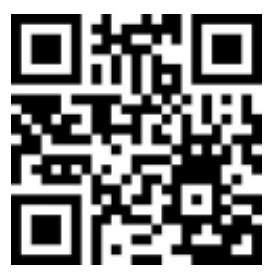

received

October 12, 2017

accepted

December 12, 2017

published online

January 16, 2018 www.thieme.com/skullbasevideos

www.thieme.com/jnlsbvideos
DOI https://doi.org/

10.1055/s-0037-1620240. ISSN 2193-6331.
๑) 2018 Georg Thieme Verlag KG
Stuttgart · New York

License terms

다 (i) $\ominus$ (\$) 


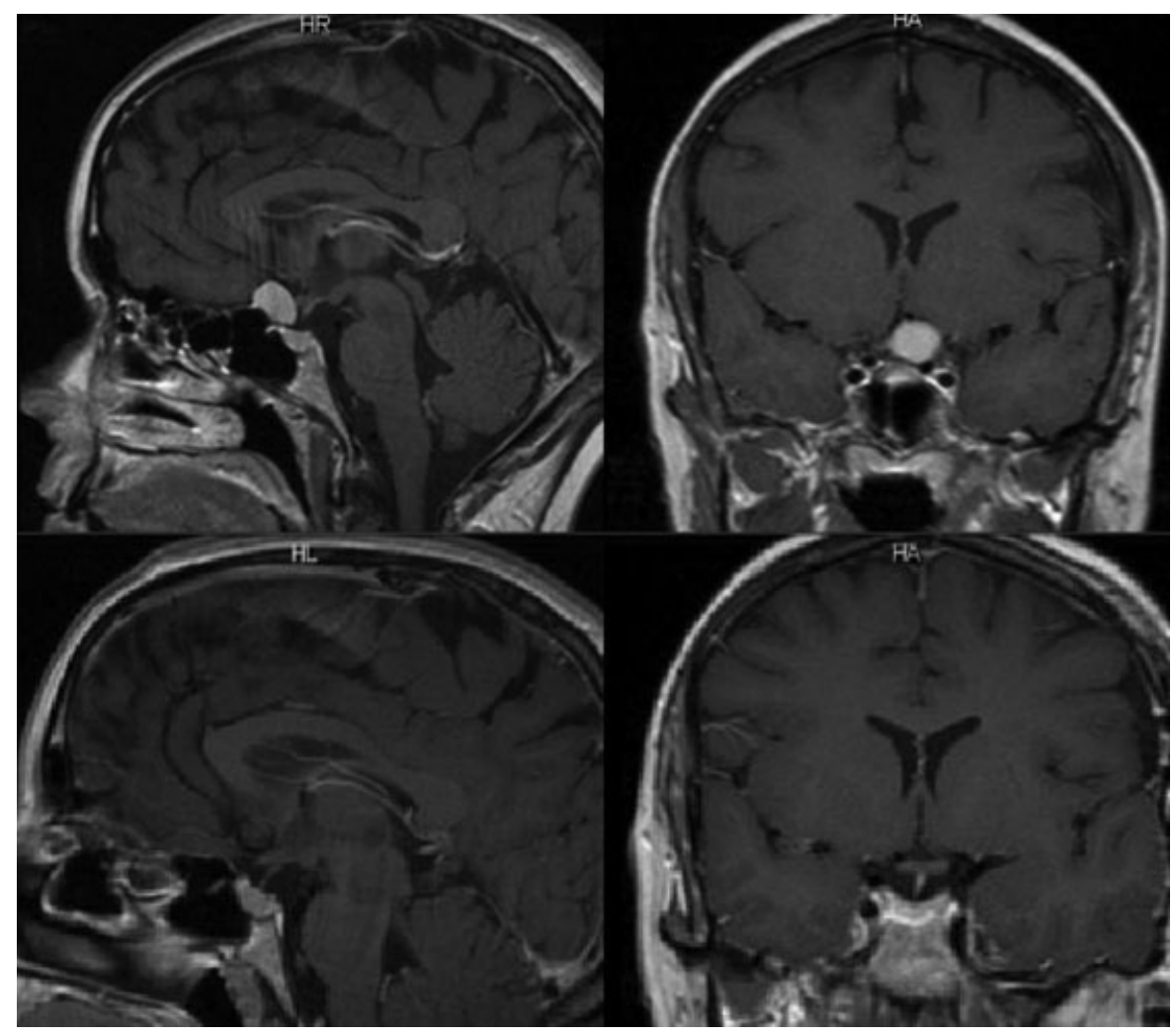

Fig. 1 Postconstrast MRI of the head. Left up: preoperative T1-weighted sagittal view. Right up: preoperative T1-weighted coronar view. Left down: postoperative T1-weighted sagittal view. Right down: postoperative T1weighted coronar view. MRI, magnetic resonance imaging.

\section{References}

1 Arnautović KI, Al-Mefty O, Angtuaco E. A combined microsurgical skull-base and endovascular approach to giant and large paraclinoid aneurysms. Surg Neurol 1998;50(06):504-518; discussion $518-520$

2 Chaddad Neto F, Doria Netto HL, Campos Filho JM, Reghin Neto M, Silva-Costa MD, Oliveira E. Orbitozygomatic craniotomy in three pieces: tips and tricks. Arq Neuropsiquiatr 2016;74(03): 228-234

3 Yasargil MG. Microneurosurgery (CNS Tumors: Surgical Anatomy, Neuropathology, Neuroradiology, Neurophysiology, Clinical Considerations, Operability, Treatment Options (Microneurosu)). Vol. IVA. New York, NY: Thieme Medical Publishers; 1994 